\title{
SUPERAÇÃO DA VIOLÊNCIA E CONSTRUÇÃO DA PAZ
}

Cardeal Orani João Tempesta, O.Cist. Arcebispo Metropolitano de São Sebastião do Rio de Janeiro ${ }^{1}$

Primeiramente, desejo louvar a iniciativa da PUC-Rio em realizar esta "Semana da Cultura Religiosa", no contexto da celebração dos 450 anos da Cidade do Rio de Janeiro e ainda vivendo as ressonâncias da Campanha da Fraternidade deste ano.

Considero o tema que me foi proposto: "Superação da violência e construção da paz", em uma oportuna continuidade com a visita do Cardeal Turkson (Presidente do Pontifício Conselho Justiça e Paz) por ocasião do Simpósio internacional que esta Universidade realizou sobre a Cultura da Paz e da Justiça diante de um mundo em conflito.

Os questionamentos do Cardeal Turkson, em seus vários pronunciamentos, nos colocam a caminho de possíveis soluções. Começamos por nós mesmos. Como, na grande cidade, encontrar a presença de Deus e levar a cultura do encontro e da paz? Diante de tantas situações calamitosas, continuaremos a nos silenciar como se nada estivesse acontecendo?

É certo que as nossas sociedades, tanto urbanas, sobretudo das metrópoles, e também as rurais, mudaram muito com a escalada da violência nos últimos tempos, de modo que já não há mais reciprocidade entre as pessoas; elas falam com as outras, não raras vezes, precavidas de poderem estar sendo vítimas de um golpe estelionatário ou mesmo de um "estudo" para serem, futuramente, assaltadas ou sequestradas. Nem os mais idosos escapam. Isso gera desconfiança, medo e a consequente falta de caridade. A cultura da cordialidade brasileira, conhecida até no exterior, parece demasiadamente ameaçada, sem que haja uma resposta à altura.

Tudo isso sem falar nos conflitos de guerras espalhados pelo mundo, nos quais centenas de milhares de pessoas já perderam suas vidas, dentre elas famílias inteiras inocentes e alheias aos problemas causados por disputas de poder, sejam de que tipos forem, sempre tão contrárias à paz que Cristo nos veio trazer.

Vez ou outra são reacesos problemas antigos ou alimentados novos, de modo que o próprio Papa Francisco chegou a falar que estamos no contexto de uma 3 ${ }^{\underline{a}}$ Guerra Mundial, tamanha a força da violência que testemunhamos nos nossos tempos. Tempos de grandes avanços científico-tecnológicos, mas ausentes, não poucas vezes, de humanidade, de caridade, de amor ao próximo, o que gera a frieza para com o semelhante e a indiferença para com o mal.

Também falta paz aos setores mais frágeis das nossas sociedades em diversas partes do mundo, de modo que na recente Encíclica Laudato Si', o Papa Francisco exorta insistentemente quando ao dilema dos mais pobres. Ele o faz não apenas para relembrar

\footnotetext{
1 Palestra proferida por ocasião da VII Semana da Cultura Religiosa da PUC-Rio, cujo tema central foram as Políticas Públicas na cidade do Rio, "Paz e Esperança se abraçarão", 16 de setembro de 2015.
} 
chavões que possam inspirar a odiosa luta de classes, mas, sim, para sustentar a opção preferencial, porém não exclusiva nem excludente, para com aqueles que não têm voz e nem vez em um mundo marcado pela busca incessante do lucro e do poder.

Aquele que nada produz é relegado à cultura do descarte. Estão aqui, como sempre recorda o Santo Padre, as crianças indefesas no ventre materno, tidas por alguns como meros amontoados de células, mas não uma vida humana como todas as outras. Daí a violência do aborto a ameaçá-las ainda antes de verem a luz do dia; os idosos sozinhos, que tanto fizeram pela humanidade, vivem quais prisioneiros de guerra em alguns países, com medo de irem ao médico para uma consulta de rotina, serem diagnosticados com problemas graves e sofrerem a eutanásia compulsória. Ou seja, não serve, mata. É a lógica da indiferença que foge da paz e gera o medo.

Outro grupo atingido pela ausência de paz é a dos adolescentes e jovens que, sem trabalho ou estudo, ficam à margem de uma sociedade excludente, na qual parece haver uma seleção desumana, com lugar apenas para os fortes ou preparados. Os demais podem cair em uma escravidão terrível de vícios e crimes que não se curam com prisões, mas, sim, com métodos educativos abrangentes, capazes de chegar a todos de verdade e sem omissões da sociedade em geral, especialmente do poder público, que se propõe a dar uma educação de qualidade ao nosso povo.

Ainda nomeamos outras formas de violência que não podem deixar de ser registradas em nossos dias, que são a perseguição sangrenta às minorias religiosas, especialmente aos cristãos em alguns países dominados por radicais de vários segmentos religiosos ou filosóficos, com destaques para a Índia, o Oriente Médio, a China ou certas regiões da África, onde também existem conflitos raciais há muito tempo, ou as perseguições mais veladas nos países ditos democráticos, mas que impedem o livre exercício da liberdade religiosa e de consciência. Até mesmo no Brasil, a objeção de consciência, entendida como um direito humano básico de se opor a tudo aquilo que contraria nossos princípios religiosos, filosóficos ou pacifistas, vem sendo ameaçada e pode mesmo ser supressa, caso as forças vivas da Nação não ergam suas vozes, dentro da lei e da ordem, mas com firmeza, contra essa forma de violência disfarçada, porém muito intolerante.

Os Bispos do Brasil na Assembleia Geral do ano passado pediram que este ano fosse o Ano da Paz. Diante de tanta violência e insegurança votamos para que assim o fosse. A partir do Advento de 2014, iniciando o novo ano litúrgico, até o Natal deste ano de 2015, as iniciativas e orações para comemorar este ano deveriam estar presentes em nosso trabalho pastoral como um tema transversal, ou seja, que estivesse atravessando por todas as iniciativas pastorais em nossa Arquidiocese.

Vivemos uma cultura de violência fomentada por diversos ciclos viciosos, presentes em todos os lugares: na mídia, nos brinquedos, no trânsito. Isso somado à individualidade e à busca 
pela satisfação imediata, faz com que as pessoas sejam menos capazes de lidar com suas frustrações, e estejam mais propensas a transformar pequenos atritos em grandes confrontos.

A paz enfrenta atualmente uma realidade que se pode denominar paradoxal: ao mesmo tempo em que ela é violada em cada quarteirão, bairro, fronteira, país ou etnia, é também reclamada, com a mesma intensidade da sua violação, em cada discurso e manifestação em prol do bem comum, da não violência, dos direitos humanos, dos direitos da mulher e da criança.

Religiões, líderes religiosos e políticos enfatizam a paz em suas falas ou escritos como realidade que não pode ser postergada. Basta reportar alguns discursos dos últimos Papas, com suas pregações ou encíclicas ao mundo. Ou Dalai Lama e tantos outros que promovem a paz.

Diante desse quadro sombrio, contudo bastante incompleto, alguns seriam levados ao desespero. Afinal, que fazer?

A paz não pode sobreviver sem um pacto, sem uma aliança ampla, que seja fruto do conjunto de todos os esforços humanos em vista da sobrevivência planetária.

A não-violência não é apenas um ideal a ser buscado, mas uma forma permanente de vida, baseada na justiça e na inclusão social. É preciso cuidar do outro com o verdadeiro sentido da palavra. Quem aprofunda este caminho percebe que os atos violentos - assaltos, sequestros, assassinatos, manifestações de racismo, de discriminação social e outras injustiças - são apenas expressões ou consequências da estrutura da sociedade, firmada, ela própria, na violência.

A prática da não-violência começa na desmontagem concreta e ideológica da violência em toda a sua amplitude. A guerra e o armamentismo parecem, então, absurdos, principalmente em um mundo que gasta por ano mais de 500 bilhões de dólares com armas e não tem dinheiro para alimentar milhões de crianças, ou cuidar da saúde das vítimas da Aids na África.

O desenvolvimento da cultura da paz começa pela vida cotidiana de cada um. Essa consciência passa inevitavelmente pela família e pela escola. É na família que a criança começa a desenvolver o seu perfil e caráter. É na escola, com o estudo, que aumentamos a nossa liberdade. Porque a liberdade só se constrói quando se tem uma noção de quais são as opções. O verdadeiro ensino religioso nas escolas daria um ótimo passo para essa cultura de entendimento e paz. Porém a intolerância ideológica procura dificultar e questionar cada vez mais essa possibilidade. O futuro saberá julgar as opções erradas de hoje. A cultura da paz e o cuidado pelo falso proselitismo passam pela educação religiosa que os pais não podem deixar de dar aos seus filhos, incutindo neles o senso da paz que só o Cristo Ressuscitado pode dar a cada um de nós. Se eu tenho só uma opção na minha frente, que liberdade é essa? Mas se eu sei que existem muitos caminhos, a minha liberdade será vivida com mais plenitude. Somente através da educação a pessoa se torna mais consciente e, consequentemente, mais humana

Voltando ao pensamento do Cardeal Turkson, destaco como ele recordou que a paz é irmã da justiça. O caminho para a não violência passa pelo respeito à diversidade de culturas, 
raças, religiões. Ficamos preocupados com os rumos fanáticos de intolerância que estão se instalando também em nosso país. Se a relação com o outro for profunda, implica o desafio de repensar a realidade e as relações sociais a partir de outros critérios e paradigmas. Desenvolver esta cultura da paz começa pela vida cotidiana de cada um. Demanda uma autêntica conversão pessoal.

A primeira atitude do cristão é converter o próprio coração, a fim de que o mundo à sua volta seja melhor, pois, ao contrário do que prega a sociedade individualista, nós somos, na humanidade, solidários uns para com os outros, de modo que o bem que fazemos ou deixamos de fazer repercute na vida dos nossos irmãos e irmãs de forma benéfica ou trágica.

A segunda atitude é buscarmos nos aliar a grupos sérios, de caráter religioso ou não, que trabalham pela paz e pelo bem do próximo, por meio da caridade. Seremos uma gotinha no oceano, mas ali faremos a diferença que só o nosso trabalho pode fazer: o pouco com Deus é tudo!

Nada disso, no entanto, se consegue sem a oração, alma da alma cristã, conforme se referem alguns autores entendidos no caminho da espiritualidade. Reflitamos, rezemos e ajamos dentro de nossas possibilidades para que a paz realmente frutifique em nosso meio, começando em nossa casa, no trabalho, na escola, enfim, nos nossos ambientes cotidianos, para daí se espalhar, positivamente, por toda a sociedade, com a graça de Deus e a intercessão de sua Mãe Maria Santíssima, a Rainha da Paz.

Concluo com um comentário da agência do Vaticano, que nos fala sobre o anúncio do Dia Mundial da Paz 2016: "A paz deve ser conquistada: não é um bem que se obtém sem esforços, sem conversão, sem criatividade e sem dialética. Trata-se de sensibilizar e formar o sentido de responsabilidade em relação às graves questões que afligem a família humana, como o fundamentalismo e seus massacres, as perseguições por causa da fé e de pertença étnica, as violações da liberdade e dos direitos dos povos, o abuso e a escravidão das pessoas, a corrupção e o crime organizado, as guerras que causam o drama dos refugiados e dos emigrantes forçados".

Prosseguindo: "A mensagem de 2016 pretende ser um ponto de partida para todas as pessoas de boa vontade, em particular aquelas que atuam na educação, na cultura e nos meios de comunicação, para que ajam, cada uma segundo suas próprias possibilidades e de acordo com as melhores aspirações, para construírem juntas um mundo mais consciente e misericordioso e, portanto, mais livre e mais justo".

Justamente aqui, no ambiente acadêmico, onde se formam futuras lideranças de nosso país, acredito que se devam cultivar esses princípios. Que esta atitude nos impulsione para outras transformações em nossas vidas e em nossas comunidades com atitudes concretas de misericórdia e de paz. O Jubileu da Misericórdia será um ótimo caminho para, além da justiça, construirmos a paz em nossas fronteiras, pois "Deus habita na cidade", e em Cristo temos a Paz! 